\title{
Association of coagulase-negative staphylococcal species, mammary quarter milk somatic cell count, and persistence of intramammary infection in dairy cattle
}

\author{
P. R. Fry, ${ }^{*}$ J. R. Middleton, ${ }^{* 1}$ S. Dufour, $†$ J. Perry, $\ddagger$ D. Scholl, $\dagger^{2}$ and I. Dohoo \\ *Department of Veterinary Medicine and Surgery, University of Missouri, Columbia 65211 \\ †Department of Pathology and Microbiology, University of Montreal, Quebec, Canada J2S 7C6 \\ $\ddagger$ Production Animal Health Centre, University of Adelaide, Australia 5371 \\ §Department of Health Management, University of Prince Edward Island, Charlottetown CIA 4P3, Canada
}

\section{ABSTRACT}

This study was conducted to evaluate the association between subclinical intramammary infection (IMI) with coagulase-negative staphylococci (CNS), mammary quarter milk somatic cell count (SCC), and persistence of IMI in dairy cattle. Convenience samples of CNS isolates harvested from milk samples of subclinically infected mammary quarters collected between 4 and 2 wk before drying-off, between 2 wk before drying-off and the day of drying-off, within $24 \mathrm{~h}$ after calving, between 1 and 2 wk after calving, and during lactation were evaluated. Isolates were obtained from the Canadian Bovine Mastitis Research Network culture bank and were identified to the species level using $r p o \mathrm{~B}$ gene sequencing. Cow and quarter-level data were obtained from the Canadian Bovine Mastitis Research Network database and used for statistical analyses. In addition, for mammary quarters that had more than one isolation of the same CNS species at different time points, the isolates were evaluated using pulsed-field gel electrophoresis to identify persistent IMI. Milk SCC was compared between mammary quarters infected with different CNS species and to a cohort of uninfected mammary quarters. A total of 877 isolates from 643 mammary quarters of 555 cows on 89 Canadian dairy farms were identified to the species level. Twenty different species were identified, with Staphylococcus chromogenes being the most common species identified (48\% of isolates), followed by Staphylococcus simulans (19\%) and Staphylococcus xylosus (10\%). Of the 20 species identified, only 9 species were found in persistently infected quarters. Milk SCC was significantly higher in the CNS-infected mammary quarters than in the uninfected control quarters for 8 of the 20 species

\footnotetext{
Received October 30, 2013.

Accepted April 30, 2014.

${ }^{1}$ Corresponding author: middletonjr@missouri.edu

${ }^{2}$ Current address: Agricultural Experiment Station, South Dakota State University, Brookings 57007.
}

studied. Also, mean SCC differed significantly between mammary quarters infected with different CNS species. Within a given species, a high degree of variability was noted in milk SCC. These data corroborate recent data from Europe with regard to the predominance of certain species of CNS (e.g., Staph. chromogenes). In addition, some species of CNS appear to have a greater effect on milk SCC. Finally, some CNS species are associated with persistent IMI suggesting that some species (e.g., Staph. chromogenes and Staph. simulans) are better host-adapted, whereas others may have an environmental reservoir.

Key words: coagulase-negative staphylococcus, mastitis, bovine

\section{INTRODUCTION}

The mastitis prevention program put forth by the National Mastitis Council has resulted in improved control of contagious mastitis pathogens on well-managed dairy herds (National Mastitis Council, 2009). As of the implementation of this program, CNS have become the most prevalent group of bacteria found in bovine milk samples in some areas of the world (Pitkälä et al., 2004; Tenhagen et al., 2006; Sampimon et al., 2009). This finding has raised concerns about the overall importance of CNS in milk quality and mastitis.

Currently, the role of the different CNS species in bovine mastitis is not completely understood. Coagulase-negative staphylococci have been cultured from the milk of cows with and without an elevated milk SCC (Thorberg et al., 2009), from the apex of the teat, from other body sites on the cow, and from the environment (Taponen et al., 2008; Piessens et al., 2011). As a group, CNS have been shown to induce only a mild inflammatory reaction in infected quarters, and CNS IMI will most often remain subclinical (Schukken et al., 2009). Some authors, however, consider CNS to be true mastitis pathogens, as they have also been associated with chronic infections (Gillespie et al., 2009) and may carry virulence factors important in mastitis 
pathogenesis (Zhang and Maddox, 2000). In contrast, other studies have found higher milk production in cows with CNS IMI (Compton et al., 2007; Schukken et al., 2009). Conflicting results as to the importance of CNS as mastitis pathogens is likely due to the failure to acknowledge variations within and between these species.

Unfortunately, the number of studies that have identified CNS isolates to the species level is somewhat limited. Also, comparison of the results between studies is difficult because, until recently, many studies used various phenotypic speciation techniques. Phenotypic speciation methods are poorly adapted for identifying CNS isolates of bovine origin (Zadoks and Watts, 2009). Genotypic speciation methodologies have recently been validated for samples of bovine origin. These methods are increasingly being used in research to differentiate CNS isolates because of higher reproducibility and typeability (Mellmann et al., 2006).

Using molecular techniques that allow accurate speciation and fingerprinting of the CNS species, recent research has found variations among species, including effects on SCC, persistence of infection, and epidemiological behavior. For example, Staphylococcus chromogenes, Staphylococcus haemolyticus, Staphylococcus epidermidis, and Staphylococcus simulans have been associated with persistent infections (Piessens et al., 2011; Supré et al., 2011). One study found the same amplified fragment-length polymorphism type from the same mammary quarter for up to 12 repeated monthly samples (Piessens et al., 2011). Other researchers have shown Staph. chromogenes, Staph. simulans, and Staph. xylosus to have a substantial effect on milk SCC, effects comparable to that of Staphylococcus aureus (Supré et al., 2011). Diversity has also been found with regards to potential reservoirs of infection. A high level of clonality among Staph. chromogenes and Staph. epidermidis isolates was noted in one report, suggesting a more hostadapted nature of these species (Piessens et al., 2012). That same study found many different genotypes of Staph. haemolyticus and Staph. simulans in the environment and cow milk, suggesting an environmental origin of these species.

To the best of our knowledge, no North American studies have been published that used genotypic speciation of CNS isolates and correlated these data with inflammation or persistence of IMI in the mammary gland. One previous North American study found that, within a herd, an average of $15 \%$ of cows were infected with CNS, and these cows had a higher milk production than culture-negative cows (Schukken et al., 2009). A more recent publication that evaluated CNS IMI during lactation on 90 Canadian dairy herds found a prevalence of $43 \%$ (Dufour et al., 2012). Although these studies screened large numbers of herds, they did not speciate CNS isolates, and therefore were unable to associate any production parameters with specific species of CNS. Another study conducted in the United States found Staph. chromogenes to be the most prevalent species of CNS (48\%), followed by Staphylococcus hyicus (26\%), and Staph. epidermidis (10\%), although that study used a phenotypic speciation method (Gillespie et al., 2009).

The aim of the present study was to evaluate the association between IMI with individual CNS species, milk SCC, and persistence of IMI. To examine these associations in a large population of cattle, CNS isolates from the Canadian Bovine Mastitis Research Network (CBMRN; Saint-Hyacinthe, Quebec, Canada) culture collection were obtained for genotypic speciation.

\section{MATERIALS AND METHODS}

\section{Sample Selection}

A convenience sample of CNS isolates was obtained from the CBMRN culture collection for speciation. This collection of mastitis pathogen isolates originated from a 2-yr study conducted on a cohort of 91 Canadian dairy farms in the years 2007 and 2008, as described by Reyher et al. (2011). During that study, mammary quarter milk samples were collected at regular intervals from cows on the participating farms. Briefly, during 4 different sampling periods between January 2007 and December 2008, 15 apparently normal milking cows were selected in each herd. Mammary quarters of these cows were sampled 3 times at 3 weekly intervals during winter 2007, winter 2008, and summer 2008. Additionally, mammary quarters were sampled once weekly for 7 wk during summer 2007. Furthermore, 15 cows were selected in each herd in 2007 and again in 2008 to follow IMI over the dry period. Mammary quarters of these cows were sampled twice before drying off (at 4 to $2 \mathrm{wk}$ before drying off and between 2 wk and drying-off) and twice after calving (within $24 \mathrm{~h}$ of calving and from 1 to 2 wk after calving). As cows were randomly selected, and given the relatively small number of milking cows in these herds (mean $=85$ cows $/$ herd; range $=32-326$ cows/herd), many cows were selected in more than one series, which resulted in some mammary quarters being sampled up to 23 times over the period of the study. Bacterial isolates cultured from various time points within the dairy production cycle were preserved and available for further characterization. For inclusion of isolates in the CBMRN culture collection, the mammary quarters had to yield growth of at least $10 \mathrm{cfu}$ of morphologically similar CNS from a $10-\mu \mathrm{L}$ inoculum of milk (i.e., $\geq 1,000 \mathrm{cfu} / \mathrm{mL}$ ). This diagnostic criteria was based on the National Mastitis Council guidelines 
regarding definition of IMI (National Mastitis Council, 1987), which prevailed when the CBMRN cohort study was conducted.

The samples selected for the current study were from subclinical IMI. Based on review of the CBMRN database, 1,555 isolates morphologically characterized as CNS were isolated from 643 mammary quarters of 555 cows in 89 herds. The number of times CNS was isolated from a given mammary quarter ranged from 1 to 10 times (median $=2$ isolations per quarter). Due to budgetary restrictions, not all CNS isolates cultured from a given mammary quarter were characterized. A total of 877 CNS isolates originating from the 643 mammary quarters were studied. All available isolates were studied for 384 of the 643 mammary quarters [ $\mathrm{n}=494$ isolates; median $=1$ (range: $1-5$ ) isolate per quarter], whereas only some of the available isolates were studied for the remaining 259 mammary quarters [ $\mathrm{n}=383$ isolates; median $=1$ (range: $1-4$ ) isolate per quarter]. Distribution of isolates by stage of lactation was 343 isolates from mammary quarter milk samples collected before dry off ( $\leq 4$ wk from dry off), 143 isolates from early lactation ( $\leq 2$ wk after calving), and 391 isolates from apparently normal mammary quarters during lactation. Distribution of isolates from different stages of the production cycle reflected the needs of associated studies being performed by CBMRN collaborators that required the species identification data. Additionally, for this purpose, based on initial screening of the database, isolates from apparently new CNS IMI (quarters that were free of CNS at drying off or for 2 successive lactating period samples and that later became positive to CNS at calving or on the following sampling, respectively), persistent CNS IMI (quarters for which CNS could be retrieved before and after the dry period or from multiple successive milk samples during the lactation), and CNS IMI that were cured (quarters positive for CNS in the pre-dry series and negative in the postcalving series or positive to $\geq 1$ sample during the lactation followed by $\geq 2$ negative samples) were included. Selected isolates were cultured from storage media and inoculated onto brain-heart infusion agar slants in screw-cap glass vials. Vials were labeled with a barcode and shipped on dry ice from the University of Montreal to the University of Missouri for further characterization.

\section{Speciation of CNS Isolates}

Isolates were speciated by amplification and sequencing of a portion of the staphylococcal rpoB gene, a conserved housekeeping gene coding for the $\beta$ subunit of RNA polymerase (Drancourt and Raoult, 2002). Briefly, selected isolates were recovered from brain-heart infusion agar slants, grown on Columbia blood agar containing 5\% sheep blood (Fisher Scientific, Lenexa, $\mathrm{KS}$ ), and 1 colony was suspended in $1 \times$ Tris-EDTA buffer (Promega, Madison, WI). With the modification of a 5-min initial denaturation step, rpoB PCR was performed using published primers and run parameters according to Drancourt and Raoult (2002). The resulting PCR products were purified using a commercial kit (Invitrogen, Carlsbad, CA). Purified DNA preparations were submitted to the University of Missouri DNA Core Facility for sequencing. Sequencing reactions were performed on an automated DNA analyzer using Applied Biosystems Big Dye Terminator chemistry (Applied Biosystems, Grand Island, NY). The resulting sequences were proofread (SeqMan software, Lasergene, Dnastar Inc. Madison, WI). Sequences were compared with the GenBank database using the publicly available nucleotide-BLAST algorithm (http://www.ncbi. nlm.nih.gov/). Species identity was assigned based on a $97 \%$ or greater sequence homology with $5 \%$ difference to the next bacterial species identified (Mellmann et al., 2006).

\section{Pulsed-Field Gel Electrophoresis}

Pulsed-field gel electrophoresis (PFGE) was used to determine whether mammary quarters that had more than one isolation of the same CNS species over time were infected with the same strain type. In general, only the first and last isolate in a series within quarter was strain typed. Pulsed-field gel electrophoresis was performed according to Middleton et al. (2002). Briefly, SmaI (Invitrogen, Carlsbad, CA) digests of staphylococcal DNA were separated by PFGE in a $1 \%$ agarose gel (Pulsed Field Certified Agarose, Bio-Rad, Hercules, CA) immersed in $0.5 \%$ TBE (TRIS, Boric Acid, EDTA) buffer at $14^{\circ} \mathrm{C}$ for $20 \mathrm{~h}$ at $6 \mathrm{~V} / \mathrm{cm}$ with a 5- to 50-s pulse time on a CHEF DRIII PFGE machine (BioRad, Hercules, CA). A lambda ladder molecular weight size standard (BioRad) was used. Gels were stained with ethidium bromide and photographed by UV transillumination. Approximately 11 to 15 bands, ranging in size from approximately 48.5 to $650 \mathrm{~kb}$, were visualized for each isolate. Representative isolates from the same IMI were run side-by-side on the gel and banding patterns were visually compared between lanes. Isolates of the same species that had indistinguishable banding patterns, based on having the same number of bands and corresponding bands of the same apparent molecular weight, were considered the same strain type (Tenover et al., 1995).

\section{SCC}

Quarter milk SCC measurements were performed by the CBMRN. Briefly, mammary quarter milk samples 
were aseptically collected on farm, shipped frozen to one of the CBMRN laboratories, thawed at the time of processing, a $10-\mu \mathrm{L}$ aliquot was removed for bacterial culture, and the remaining milk had a 2-Bromo-2-nitropropane-1,3-diol preservative tablet (Broad Spectrum Microtabs II, D\&F Control Systems Inc., Dublin CA) added. Samples were then shipped overnight on ice to Maritime Quality Milk at the University of Prince Edward Island and subsequently subjected to SCC analysis. Most samples were processed on the day they were received. Samples not processed immediately were either stored frozen (if already frozen) or kept refrigerated and processed within 5 d. Somatic cell count concentrations in mammary quarter milk samples were determined using a Fossomatic cell counter (Fossomatic 4000 series; Foss Electric A/S, Hillerød, Denmark). Final results were uploaded into the CBMRN database.

\section{Data Analysis}

Somatic cell counts from mammary quarter milk samples where a given CNS species was cultured were compared with SCC of negative mammary quarter milk samples. For this purpose, negative samples from the source population were assembled; all CBMRN milk samples that did not yield any growth of any bacteria were regrouped as potential controls. Controls were randomly chosen from this pool of negative samples in a ratio of 2 control samples for 1 CNS-positive milk sample. Proportions of controls selected in each sample type category (early lactation, lactation, and drying off) were identical to those mammary quarters yielding a CNS isolate.

To determine the effect of CNS species on SCC, a linear hierarchical repeated measures mixed model was fitted to the data using the MIXED procedure of SAS (SAS Institute Inc., Cary, NC). In this model, the SCC natural logarithm of a milk sample was treated as the outcome variable and species of CNS, including negative controls as the reference category, were treated as fixed predictor variables. Number of days in milk at time of sampling and parity of the cow were included in the fixed part of the model to adjust estimates of the CNS-SCC association for confounding by these variables. To account for correlation between cows within a given herd and between quarters within a given cow, random herd and cow effects were included in the model. Milk samples collected on a given quarter more than once were considered repeated measurements. A spatial power covariance structure was used to model these repeated measures to account for the correlation between milk samples collected on the same quarter and for the variation of this correlation with the varying amount of time between sample collections. Day of sample collection within a series of samples collected on a quarter was used for this purpose as a fixed predictor. The model was

$$
\begin{gathered}
\log \mathrm{SCC}_{i j k l}=\beta_{0}+\beta_{1} \mathrm{CNS}_{\text {Species }} i j k l+\beta_{2} \mathrm{DIM}_{i j k l} \\
+\beta_{3} \mathrm{DIM}_{i j k l}^{2}+\beta_{4} \mathrm{DIM}_{i j k l}{ }^{3}+\beta_{5} \text { Lactation Number }_{k l} \\
+\beta_{6} \mathrm{Day}_{i j k l}+v_{l}+u_{k l}+w_{j k l}+e_{i j k l},
\end{gathered}
$$

where $\log \mathrm{SCC}_{i j k l}$ is the predicted natural logarithm of SCC for the $i$ th sample of the $j$ th quarter of the $k$ th cow from the lth herd; $\beta_{0}$ is the intercept; $\beta_{1}, \beta_{2}, \beta_{3}$, $\beta_{4}, \beta_{5}$, and $\beta_{6}$ are the regression coefficients for species of CNS, DIM (centered on 200 DIM), DIM quadratic and cubic terms (to correct for the nonlinear relationship between DIM and $\operatorname{logSCC}$ ), parity, and day of the sampling within a series, respectively; and $v_{l}, u_{k l}, w_{j k l}$, and $e_{i j k l}$ are the herd random effect, cow random effect, quarter repeated effect, and sample error term, respectively (approximate normal distribution assumed). The Tukey-Kramer procedure was used for post hoc comparisons.

Pulsed-field gel electrophoresis results within a given mammary quarter were evaluated. Mammary quarters that had the same strain type of CNS (same species and PFGE banding pattern) isolated from more than one sample period were defined as persistent infections. The numbers and proportions of persistently infected mammary quarters were calculated along with the median (range) for time between the first and last sample positive for the same CNS species and strain type within a mammary quarter. No statistical comparisons were made between species due to the small numbers of mammary quarters evaluated within herd.

\section{RESULTS}

A total of 877 CNS isolates from 643 mammary quarters of 555 cows in 89 herds were successfully identified to the species level. The median number (range) of cows and mammary quarters studied within herd was $6(1-19)$ and 7 (1-20), respectively. Twenty different CNS species were identified, with Staph. chromogenes being the most common species identified ( $48 \%$ of isolates), followed by Staph. simulans (19\%) and Staph. xylosus (10\%; Table 1). Within each sample category (early lactation, lactation, and drying off) these 3 CNS species also predominated (Table 1 ).

Coagulase-negative staphylococci were isolated only once from 296 of the 643 mammary quarters (46\%). For a further 167 of the 643 mammary quarters (26\%), only 1 of the multiple isolates recorded in the database (available isolate range $=2-10$ isolates per quarter) 
Table 1. Absolute number and proportion of specific CNS species among all CNS isolates within a given sample category

\begin{tabular}{|c|c|c|c|c|c|c|c|c|}
\hline CNS species & \multicolumn{2}{|c|}{ Dry off ${ }^{1}$} & \multicolumn{2}{|c|}{ Early lactation $^{2}$} & \multicolumn{2}{|c|}{ Lactating $^{3}$} & \multicolumn{2}{|c|}{ Total } \\
\hline Staphylococcus chromogenes & 161 & 47 & 62 & 43 & 194 & 50 & 417 & 48 \\
\hline Staphylococcus xylosus & 47 & 14 & 11 & 8 & 34 & 9 & 92 & 10 \\
\hline Staphylococcus haemolyticus & 42 & 12 & 10 & 7 & 19 & 5 & 71 & 8 \\
\hline Staphylococcus epidermidis & 17 & 5 & 8 & 6 & 9 & 2 & 34 & 4 \\
\hline Staphylococcus sciuri & 2 & 1 & 1 & 1 & 5 & 1 & 8 & 1 \\
\hline Staphylococcus arlettae & 6 & 2 & 1 & 1 & 1 & $<1$ & 8 & 1 \\
\hline Staphylococcus capitis & 3 & 1 & 1 & 1 & 3 & 1 & 7 & 1 \\
\hline Staphylococcus saprophyticus & 0 & 0 & 2 & 1 & 3 & 1 & 5 & 1 \\
\hline Staphylococcus equorum & 3 & 1 & 0 & 0 & 2 & 1 & 5 & 1 \\
\hline Staphylococcus gallinarium & 1 & $<1$ & 1 & 1 & 3 & 1 & 5 & 1 \\
\hline Staphylococcus vitilinus & 0 & 0 & 1 & 1 & 0 & 0 & 1 & $<1$ \\
\hline Total & 343 & & 143 & & 391 & & 877 & \\
\hline
\end{tabular}

${ }^{1}$ Dry off is defined as $\leq 2 \mathrm{wk}$ from dry off.

${ }^{2}$ Early lactation is defined as $\leq 2 \mathrm{wk}$ after calving.

${ }^{3}$ Lactating is defined as $>2$ wk after calving and $>2$ wk from dry off.

${ }^{4}$ Percentages listed were rounded to the nearest whole number.

was represented in the convenience sample and thus identified to the species level in the current study. Hence, a total of $180(28 \%)$ mammary quarters had a CNS species isolated from multiple sample time points and were included in the batch of isolates obtained for the current study. Of these mammary quarters, 14 had a different CNS species isolated at each of the investigated time points and thus were not eligible for PFGE. Therefore, isolates from $166(26 \%)$ mammary quarters $(\mathrm{n}=376$ isolates) were eligible for PFGE DNA fingerprinting. These mammary quarters had 2 to 5 CNS isolates of the same species from different sample collection time points available for characterization. Interpretable PFGE data were generated for 140 of these 166 mammary quarters ( $84 \% ; n=320$ isolates). For the remaining mammary quarters, the PFGE banding patterns were unreadable $(\mathrm{n}=6$ mammary quarters; 13 isolates) or an isolate in the series was missing or could not be recovered from storage media $(\mathrm{n}=20$ mammary quarters; 43 isolates). For 9 mammary quarters from which multiple isolates were available $(\mathrm{n}=34$ total isolates; range $=3$ to 5 isolates/quarter), only some of the isolates in the series were subjected to PFGE fingerprinting ( $\mathrm{n}=25$ isolates subjected to PFGE). In the majority of cases (128 of 140 mammary quarters; $91 \%$ ), the isolates from the same quarter had the same PFGE banding pattern (Table 2). Of the 20 CNS species identified overall, only 9 CNS species were found in persistently infected mammary quarters (Table 2). True duration of infection could not be determined because the onset of IMI was not known, and the random nature of the sampling strategy at the mammary quarter level could not guarantee that all possible CNS isolates were available for study. The median time between isolations of the same species and strain-type from a given mammary quarter was $21 \mathrm{~d}$ (range $=7-340 \mathrm{~d}$; Table 2). Twelve of the 140 mammary quarters (9\% of quarters; $\mathrm{n}=26$ isolates) with the same CNS species at more than one time point had a different PFGE banding pattern at the different sampling periods and were considered to be infected with unrelated CNS IMI at the different sample periods.

Mean milk SCC was significantly higher in mammary quarters infected with Staph. chromogenes, Staph. simulans, Staph. xylosus, Staph. haemolyticus, Staph. epidermidis, Staphylococcus warnerii, Staphylococcus capitis, and Staph. hyicus than uninfected control mammary quarters $(P \leq 0.05$; Table 3$)$. Additionally, differences in milk SCC were detected between CNS species (Table 3). Staphylococcus chromogenes and Staph. simulans had significantly higher mean SCC compared with Staph. xylosus and Staphylococcus cohnii $(P \leq 0.05)$. Staphylococcus simulans mean SCC was also significantly higher than Staphylococcus sciuri $(P<0.05)$, and Staph. epidermidis and Staph. haemolyticus both had mean SCC that were significantly higher than Staph. cohnii $(P \leq$ 
Table 2. Association between CNS species and median number of days between first and last positive sample (in the convenience sample) from a given mammary quarter ${ }^{1}$

\begin{tabular}{|c|c|c|}
\hline CNS species & $\begin{array}{c}\text { Mammary quarters } \\
\text { with more than } 1 \\
\text { isolation of the same } \\
\text { CNS species and } \\
\text { PFGE strain-type, n }(\%)\end{array}$ & $\begin{array}{l}\text { Median (range) number } \\
\text { of days between first } \\
\text { and last sample positive } \\
\text { from a given mammary } \\
\text { quarter having the same } \\
\text { CNS species and } \\
\text { PFGE strain-type }\end{array}$ \\
\hline Staphylococcus chromogenes & $77(60 \%)$ & $21(7-224)$ \\
\hline Staphylococcus simulans & $30(23 \%)$ & $28(7-340)$ \\
\hline Staphylococcus xylosus & $10(8 \%)$ & $18(8-42)$ \\
\hline Staphylococcus haemolyticus & $5(4 \%)$ & $15(7-20)$ \\
\hline Staphylococcus cohnii & $2(2 \%)$ & $16(15-17)$ \\
\hline Staphylococcus epidermidis & $1(<1 \%)$ & 14 \\
\hline Staphylococcus warneri & $1(<1 \%)$ & 15 \\
\hline Staphylococcus capitis & $1(<1 \%)$ & 29 \\
\hline Staphylococcus nepalensis & $1(<1 \%)$ & 7 \\
\hline
\end{tabular}

${ }^{1}$ Quarters were considered to have a persistent infection if the same species and pulsed-field gel electrophoresis (PFGE) strain-type were identified at the first and last sampling. Percentages shown are the percent of mammary quarters with a persistent IMI identified to be associated with a given CNS species among the total number of mammary quarters with a persistent CNS IMI (e.g., 128 mammary quarters had a persistent CNS IMI, $60 \%$ or 77 of these were Staph. chromogenes IMI).

0.05). Within a given CNS species, a high degree of variability was noted in milk SCC (Figure 1).

\section{DISCUSSION}

To the best of our knowledge, the current study is the first completed in North America that has character- ized CNS isolates from multiple herds using genotypic speciation and associated IMI caused by these genotypically identified species with milk SCC and persistence of infection. One previous study, performed in the United States, used phenotypic speciation of CNS and found Staph. chromogenes to be the most commonly identified species (Gillespie et al., 2009), similar to the results

Table 3. Means and 95\% upper and lower CI for mammary quarter SCC (adjusted for parity and stage of lactation) associated with each CNS species in 643 subclinically infected and 1,756 culture-negative control mammary quarters

\begin{tabular}{|c|c|c|c|}
\hline \multirow[b]{2}{*}{ CNS species } & \multirow{2}{*}{$\begin{array}{c}\text { Mean SCC, } \\
\times 1,000 \text { cells } / \mathrm{mL}\end{array}$} & \multicolumn{2}{|c|}{$95 \% \mathrm{CI}$} \\
\hline & & Lower & Upper \\
\hline Staphylococcus chromogenes* & $171.9^{\mathrm{ac}}$ & 148.4 & 199.2 \\
\hline Staphylococcus simulans* & $265.6^{\mathrm{a}}$ & 211.8 & 333 \\
\hline Staphylococcus xylosus* & $92.6^{\mathrm{bd}}$ & 70.2 & 122.2 \\
\hline Staphylococcus haemolyticus* & $169.9^{\text {acd }}$ & 124 & 232.8 \\
\hline Staphylococcus epidermidis* & $211.3^{\text {acd }}$ & 134.9 & 330.9 \\
\hline Staphylococcus cohnii & $50.0^{\mathrm{b}}$ & 29.6 & 84.3 \\
\hline Staphylococcus warneri* & 233.2 & 90.4 & 601.6 \\
\hline Staphylococcus hyicus* & 286.1 & 114.9 & 712.2 \\
\hline Staphylococcus sciuri & $52.6^{\mathrm{bc}}$ & 21.8 & 127 \\
\hline Staphylococcus arlettae & 134.4 & 55.2 & 327.4 \\
\hline Staphylococcus capitis* & 214.3 & 80.8 & 568.7 \\
\hline Staphylococcus saprophyticus & 108.9 & 35.2 & 336.8 \\
\hline Staphylococcus equorum & 80.8 & 26.2 & 249.4 \\
\hline Staphylococcus gallinarium & 176.7 & 56.9 & 548.9 \\
\hline Staphylococcus auricularis & 135.8 & 38.2 & 482.9 \\
\hline Staphylococcus hominis & 80.4 & 15.7 & 413.5 \\
\hline Staphylococcus pasteuri & 38.4 & 8.9 & 166.2 \\
\hline Staphylococcus succinius & 30.4 & 7.1 & 130.2 \\
\hline Staphylococcus nepalensis & 36.3 & 3.9 & 340.7 \\
\hline Staphylococcus vitilinus & 198.4 & 15 & $2,622.1$ \\
\hline Negative control & 34.5 & 32.1 & 37.2 \\
\hline
\end{tabular}

$\overline{\mathrm{a}-\mathrm{d}}$ Least squares means SCC with different superscripts differ from each other $(P \leq 0.05$, adjusted for multiple comparisons using the Tukey-Kramer procedure).

*Least squares means SCC differs from negative controls $(P \leq 0.05$, adjusted for multiple comparisons using the Tukey-Kramer procedure). 


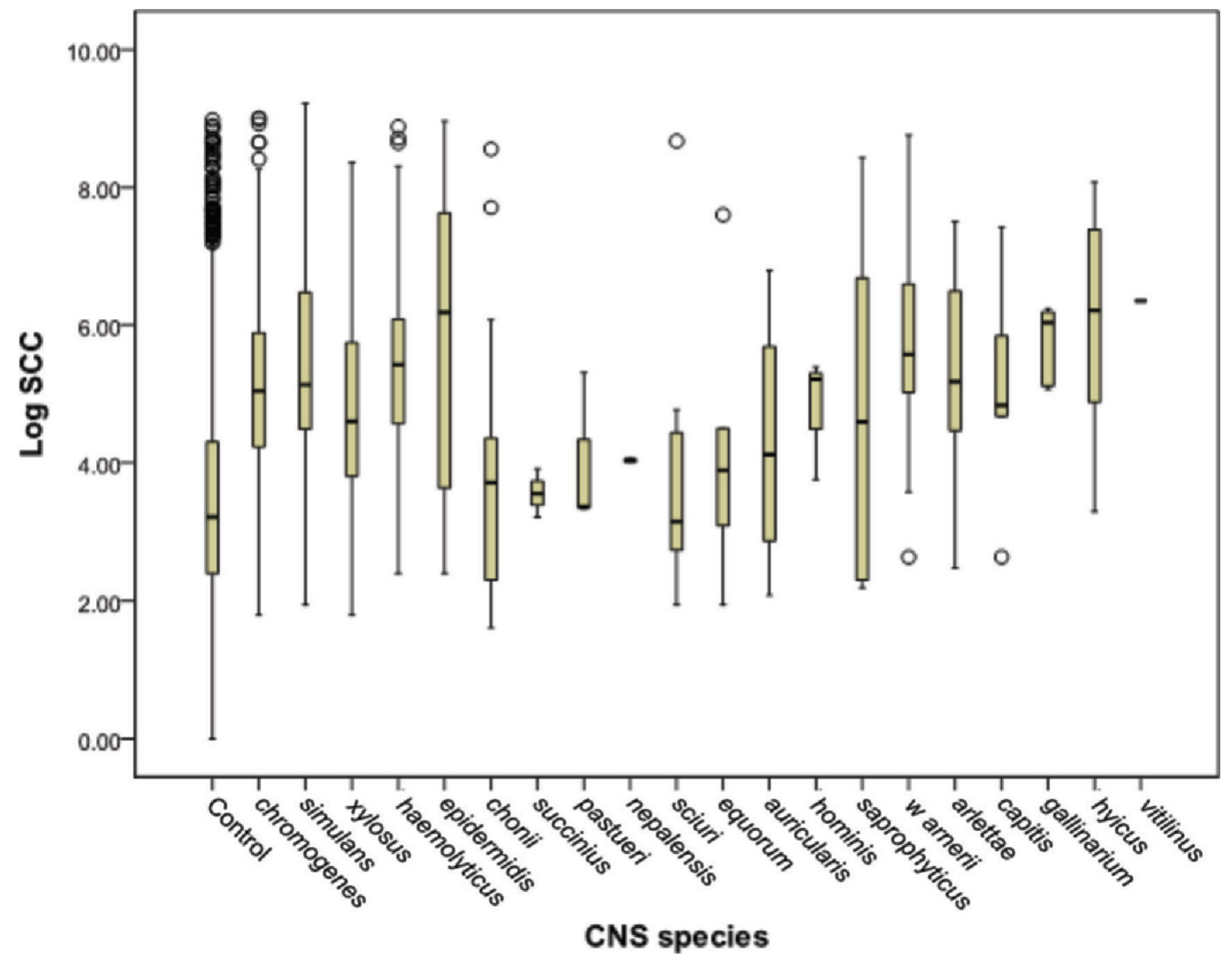

Figure 1. Box plot of log SCC for each CNS species and culture-negative control quarters. Each box contains $50 \%$ of the data, the median (line), and the upper (75th) and lower (25th) quartiles. The whiskers indicate values above and below 3 interquartile ranges from the upper and lower edges of the box, respectively. More extreme observations are represented by dots. Color version available in the online PDF.

of the present study and recent studies performed in Europe (Sampimon et al., 2009; Piessens et al., 2011). Gillespie et al. (2009) found Staph. hyicus as the second most common species in selected Tennessee dairy herds. In the current study, Staph. hyicus was found to represent a relatively low proportion $(<1 \%)$ of the isolates. Similar findings have been observed in other studies using genotypic speciation methods (Sampimon et al., 2009; Piessens et al., 2011). The discrepancy between studies is likely due to the fact that phenotypic speciation using biochemical test strips has recently been shown to have low sensitivity and specificity for discriminating Staph. chromogenes from Staph. hyicus, resulting in misclassification of isolates (Zadoks and Watts, 2009). This could explain the difference found between the current study and the results reported by Gillespie et al. (2009).

It is notable that some of the commonly identified species in this study, such as Staph. chromogenes, Staph. epidermidis, and Staph. simulans, are associated with a significant increase in SCC, whereas other species, such as Staph. cohnii, are not. Some of the more common species identified, including Staph. simulans and Staph. epidermidis, had a mean SCC above 200,000 cells/mL. Somatic cell counts at this level have been associated with decreased milk production and could affect the overall income of the dairy, especially if these specific species are highly prevalent within a herd (Schukken et al., 2003; Schukken et al., 2009; Hand et al., 2012). Being able to identify CNS isolates at the species level 
could be useful to a dairy farmer, not only to determine the cause of increased SCC, but also because some of the more commonly identified CNS species, such as Staph. chromogenes and Staph. epidermidis, have been shown to be potentially more contagious in nature (Piessens et al., 2011).

In the present study, DNA fingerprinting (PFGE) was used to determine whether the same strain type of a given CNS species was isolated from the same quarter over an extended period of time. Although DNA fingerprinting is often used to determine the relatedness of all isolates of a given species being studied, such studies are usually evaluating isolates that are epidemiologically related. In the present study, the number of isolates studied within a given herd was small, and hence it was determined inappropriate to fingerprint and perform a cluster analysis on all isolates of a given species because they were not epidemiologically related. Dufour et al. (2012) determined that, because of the very high incidence of CNS IMI, finding the same CNS species on 2 different occasions was not sufficient to define a chronic IMI. Therefore, in the present study, a persistent IMI was defined by finding the same species and the same strain type at more than one time point. Recent studies performed in the United States and Europe that have used DNA fingerprinting (amplified fragment-length polymorphism or PFGE) to confirm persistence of infection have found, similar to the present study, that some species of CNS are associated with chronic infections (Taponen et al., 2007; Gillespie et al., 2009; Supré et al., 2011). Gillespie et al. (2009) found that CNS can persist in the mammary gland for at least 10 mo. Similarly, Thorberg et al. (2009) reported that Staph. chromogenes, Staph. epidermidis, and Staph. simulans were the most common CNS species to be associated with persistent infections. However, that study only used species identification alone as the criteria for defining persistent infections. Although true duration of infection could not be determined in the present study, Staph. chromogenes and Staph. simulans were both found to be associated with persistent infections, some lasting over $200 \mathrm{~d}$, thus corroborating previous research (Aarestrup and Jensen, 1997; Thorberg et al., 2009). Further research to determine pathogen-related factors associated with persistence of infection within these species is necessary.

Although several species of CNS are associated with higher milk SCC or persistent IMI, several CNS species influence on milk SCC has been found to be no different from uninfected control mammary quarters. In the present study these species included Staph. cohnii, Staph. sciuri, Staphylococcus arlettae, Staphylococcus equorum, Staphylococcus saprophyticus, Staphylococcus gallinarium, Staphylococcus auricularis, Staphylococ- cus succinius, Staphylococcus pasteuri, Staphylococcus hominis, Staphylococcus nepalensis, and Staphylococcus vitilinus. Of these CNS species, only Staph. cohnii and Staph. nepalensis were isolated from mammary quarters with persistent infections. However, the longest time between samples yielding the same species and strain type with these 2 species was only $17 \mathrm{~d}$. A previous study has shown many of these species, including Staph. equorum, Staph. sciuri, Staph. cohnii, and Staph. saprophyticus, as being primarily of environmental origin, and therefore these species may be acting as opportunistic mastitis pathogens (Piessens et al., 2011).

With many studies now reporting CNS species as the leading cause of subclinical mastitis (Pitkälä et al., 2004; Tenhagen et al., 2006; Sampimon et al., 2009), it is necessary to understand the hazards associated with these species. For example, enterotoxin genes have been found in CNS species (Rosec et al., 1997; Park et al., 2011), and potentially even more prevalent than in Staph. aureus (de Freitas Guimarães et al., 2013). These factors could be important in human disease, especially with consumption of unpasteurized milk. It has been hypothesized that CNS species may serve as a reservoir for antimicrobial resistance determinants (Archer and Climo, 1994). One recent study found most CNS species to be susceptible to common antimicrobials used for mastitis treatment, with the exception of Staph. epidermidis, which was found to be resistant to ampicillin, erythromycin, methicillin, and pirlimycin (Sawant et al., 2009). Continuing to study CNS at the species level using appropriate speciation methods will further our understanding of these species and the risks associated with them.

Some limitations to the present study exist. One issue is the relatively high SCC in some of the culturenegative control mammary quarters (Figure 1). This likely reflects the low sensitivity of bacterial culture as a method for identifying IMI. A recent study found bacterial culture to have limited sensitivity for diagnosing an IMI with any bacterial pathogen, and requiring anything more than $100 \mathrm{cfu} / \mathrm{mL}$ to diagnose an IMI intensified the problem (Dohoo et al., 2011). Based on the threshold of 10 colonies $/ 0.01 \mathrm{~mL}$ of inoculum of milk $(1,000 \mathrm{cfu} / \mathrm{mL})$ used by CBMRN to bank isolates, as previously recommended by the National Mastitis Council (1987), the estimated sensitivity for diagnosing an IMI with any organism would have been $26.8 \%$ (Dohoo et al., 2011). Hence, it is possible that we could have some undiagnosed IMI in the negative control population of mammary quarters. That said, the median (Figure 1) and mean milk SCC (Table 3) was generally lower than the median or mean SCC recorded in mammary quarters infected with most CNS species. A second limitation of our study is the fact 
that SCC were determined using milk samples that had been frozen. Previous work has shown that when using the Fossomatic 4000 on previously frozen samples, SCC concentrations will be lower than those recorded in fresh milk samples (Barkema et. al, 1997). However, Barkema et al. (1997) reported that the decrease in SCC concentration caused by freezing was small and had little effect on the sensitivity and specificity for diagnosing an IMI. Furthermore, all samples were frozen in the current study, so any influence of freezing on the SCC data was the same among all samples and therefore should not have affected the reported comparisons between species of CNS.

Further research to determine genetic variables associated with virulence within CNS species is warranted. It is currently not well understood why species such as Staph. chromogenes and Staph. simulans are associated with a significantly higher SCC than other CNS species or why some species and strain types tend to persist within the mammary gland. Investigating virulence genes and their association with milk production and quality parameters could lead to increased understanding of the pathogenicity of these species.

\section{CONCLUSIONS}

Genotypic speciation of CNS isolated from cases of subclinical bovine mastitis from a large number of Canadian dairy farms found Staph. chromogenes, Staph. simulans, and Staph. xylosus to be the most prevalent species. Some of the highly prevalent species, such as Staph. chromogenes and Staph. simulans, were found to be associated with persistent infections and significantly higher milk SCC. These data corroborate findings from other countries and demonstrate that certain species of CNS may be better host-adapted than others or have a greater effect on udder health and milk quality.

\section{ACKNOWLEDGMENTS}

The bacterial isolates were obtained from the Canadian Bovine Mastitis Research Network (Saint-Hyacinthe, QC, Canada) culture collection. The Canadian Bovine Mastitis Research Network is supported by the Natural Sciences and Engineering Research Council of Canada (Ottawa, ON, Canada), Alberta Milk (Edmonton, AB, Canada), Dairy Farmers of New Brunswick (Sussex, NB, Canada), Dairy Farmers of Nova Scotia (Lower Truro, NS, Canada), Dairy Farmers of Ontario (Mississauga, ON, Canada), Dairy Farmers of Prince Edward Island (Charlottetown, PEI, Canada), Novalait Inc. (Quebec, QC, Canada), Dairy Farmers of Canada (Ottawa, ON, Canada), Canadian Dairy Network (Guelph, ON, Canada), Agriculture and Agri-Food
Canada (Ottawa, ON, Canada), Public Health Agency of Canada (Ottawa, ON, Canada), Innovation PEI Inc. (Charlottetown, PEI, Canada), Université de Montréal (Saint-Hyacinthe, QC, Canada), and University of Prince Edward Island (Charlottetown, PEI, Canada). This work was funded, in part, by a USDA formula fund grant awarded by the University of Missouri, College of Veterinary Medicine (Columbia, MO), Committee on Research and a graduate student research fellowship (J. Perry) from the American Association of Bovine Practitioners (Auburn, AL).

\section{REFERENCES}

Aarestrup, F. M., and N. E. Jensen. 1997. Prevalence and duration of intramammary infection in Danish heifers during the peripartum period. J. Dairy Sci. 80:307-312.

Archer, G. L., and M. W. Climo. 1994. Antimicrobial susceptibility of coagulase-negative staphylococci. Antimicrob. Agents Chemother. $38: 2231-2237$.

Barkema, H. W., J. Van Der Schans, Y. H. Schukken, A. L. W. De Gee, T. J. G. M. Lam, and G. Benedictus. 1997. Effect of freezing on somatic cell count of quarter milk samples as determined by a Fossomatic electronic cell counter. J. Dairy Sci. 80:422-426.

Compton, C. W., C. Heuer, K. Parker, and S. McDougall. 2007. Epidemiology of mastitis in pasture-grazed peripartum dairy heifers and its effects on productivity. J. Dairy Sci. 90:4157-4170.

de Freitas Guimarães, F., D. B. Nobrega, V. B. Richini-Pereira, P. M. Marson, J. C. de Figueiredo Pantoja, and H. Langoni. 2013 Enterotoxin genes in coagulase-negative and coagulase-positive staphylococci isolated from bovine milk. J. Dairy Sci. 96:28662872 .

Dohoo, I. R., J. Smith, S. Andersen, D. F. Kelton, S. Godden, and Mastitis Research Workers' Conference. 2011. Diagnosing intramammary infections: Evaluation of definitions based on a single milk sample. J. Dairy Sci. 94:250-261.

Drancourt, M., and D. Raoult. 2002. rpoB gene sequence-based identification of Staphylococcus species. J. Clin. Microbiol. 40:13331338.

Dufour, S., I. R. Dohoo, H. W. Barkema, L. Des Côteaux, T. J. DeVrie, K. K. Reyher, J.-P. Roy, and D. T. Scholl. 2012. Coagulasenegative staphylococci intramammary infection epidemiology in dairy cattle and impact of bacteriological culture misclassification. J. Dairy Sci. 95:3110-3124.

Gillespie, B. E., S. I. Headrick, S. Boonyayatra, and S. P. Oliver. 2009 Prevalence and persistence of coagulase-negative Staphylococcus species in three dairy research herds. Vet. Microbiol. 134:65-72.

Hand, K. J., A. Godkin, and D. F. Kelton. 2012. Milk production and somatic cell counts: A cow-level analysis. J. Dairy Sci. 95:13581362 .

Mellmann, A., K. Becker, C. von Eiff, U. Keckevoet, P. Schumann, and D. Harmsen. 2006. Sequencing and staphylococci identification. Emerg. Infect. Dis. 12:333-336.

Middleton, J. R., L. K. Fox, J. M. Gay, J. W. Tyler, and T. E. Besser. 2002. Influence of Staphylococcus aureus strain on mammary quarter milk somatic cell count and $N$-acetyl-beta-D-glucosaminidase activity in cattle from eight dairies. J. Dairy Sci. 85:1133-1140.

National Mastitis Council. 1987. Laboratory and Field Handbook on Bovine Mastitis. W. D. Hoard \& Sons Co., Fort Atkinson, WI.

National Mastitis Council. 2009. Recommended Mastitis Control Program. National Mastitis Council Inc., Madison, WI. http://www. nmconline.org/docs/NMCchecklistInt.pdf.

Park, J. Y., L. K. Fox, K. S. Seo, M. A. McGuire, Y. H. Park, F. R. Rurangirwa, W. M. Sischo, and G. A. Bohach. 2011. Detection of classical and newly described staphylococcal superantigen genes in coagulase-negative staphylococci isolated from bovine intramammary infections. Vet. Microbiol. 147:149-154. 
Piessens, V., S. De Vliegher, B. Verbist, G. Braem, A. Van Nuffel, L. De Vuyst, M. Heyndrickx, and E. Van Coillie. 2012. Intra-species diversity and epidemiology varies among coagulase-negative Staphylococcus species causing bovine intramammary infections. Vet. Microbiol. 155:62-71.

Piessens, V., E. Van Coillie, B. Verbist, K. Supré, G. Braem, A. Van Nuffel, L. De Vuyst, M. Heyndrickx, and S. De Vliegher. 2011. Distribution of coagulase-negative Staphylococcus species from milk and environment of dairy cows differs between herds. J. Dairy Sci. 94:2933-2944.

Pitkälä, A., M. Haveri, S. Pyörälä, V. Myllys, and T. Honkanen-Buzalski. 2004. Bovine mastitis in Finland 2001-prevalence, distribution of bacteria, and antimicrobial resistance. J. Dairy Sci. $87: 2433-2441$

Reyher, K. K., S. Dufour, H. W. Barkema, L. Des Côteaux, T. J. Devries, I. R. Dohoo, G. P. Keefe, J. P. Roy, and D. T. Scholl. 2011. The National Cohort of Dairy Farms-A data collection platform for mastitis research in Canada. J. Dairy Sci. 94:1616-1626.

Rosec, J. P., J. P. Guiraud, C. Dalet, and N. Richard. 1997. Enterotoxin production by staphylococci isolated from foods in France. Int. J. Food Microbiol. 35:213-221.

Sampimon, O. C., H. W. Barkema, I. M. Berends, J. Sol, and T. J. Lam. 2009. Prevalence and herd-level risk factors for intramammary infection with coagulase-negative staphylococci in Dutch dairy herds. Vet. Microbiol. 134:37-44.

Sawant, A. A., B. E. Gillespie, and S. P. Oliver. 2009. Antimicrobial susceptibility of coagulase-negative Staphylococcus species isolated from bovine milk. Vet. Microbiol. 134:73-81.

Schukken, Y. H., R. N. Gonzalez, L. L. Tikofsky, H. F. Schulte, C. G. Santisteban, F. L. Welcome, G. J. Bennett, M. J. Zurakowski, and R. N. Zadoks. 2009. CNS mastitis: Nothing to worry about? Vet Microbiol. 134:9-14

Schukken, Y. H., D. J. Wilson, F. Welcome, L. Garrison-Tikofsky, and R. N. Gonzalez. 2003. Monitoring udder health and milk quality using somatic cell counts. Vet. Res. 34:579-596.
Supré, K., F. Haesebrouck, R. N. Zadoks, M. Vaneechoutte, S. Piepers, and S. De Vliegher. 2011. Some coagulase-negative Staphylococcus species affect udder health more than others. J. Dairy Sci. 94:2329-2340

Taponen, S., J. Björkroth, and S. Pyörälä. 2008. Coagulase-negative staphylococci isolated from bovine extramammary sites and intramammary infections in a single dairy herd. J. Dairy Res. 75:422429 .

Taponen, S., J. Koort, J. Björkroth, H. Saloniemi, and S. Pyörälä 2007. Bovine intramammary infections caused by coagulase-negative staphylococci may persist throughout lactation according to amplified fragment length polymorphism-based analysis. J. Dairy Sci. 90:3301-3307.

Tenhagen, B. A., G. Köster, J. Wallmann, and W. Heuwieser. 2006. Prevalence of mastitis pathogens and their resistance against antimicrobial agents in dairy cows in Brandenburg, Germany. J. Dairy Sci. 89:2542-2551.

Tenover, F. C., R. D. Arbeit, R. V. Goering, P. A. Mickelsen, B. E. Murray, D. H. Persing, and B. Swaminathan. 1995. Interpreting chromosomal DNA restriction patterns produced by pulsed-field gel electrophoresis: Criteria for bacterial strain typing. J. Clin. Microbiol. 33:2233-2239.

Thorberg, B. M., M. L. Danielsson-Tham, U. Emanuelson, and K. Persson Waller. 2009. Bovine subclinical mastitis caused by different types of coagulase-negative staphylococci. J. Dairy Sci. 92:4962-4970.

Zadoks, R. N., and J. L. Watts. 2009. Species identification of coagulase-negative staphylococci: Genotyping is superior to phenotyping. Vet. Microbiol. 134:20-28.

Zhang, S., and C. W. Maddox. 2000. Cytotoxic activity of coagulase-negative staphylococci in bovine mastitis. Infect. Immun. 68:1102-1108. 